\title{
Hispanismes
}

Revue de la Société des Hispanistes Français

\section{“O jantar”, Laços de familia (1960)}

Uma leitura do conto de Clarice Lispector

"O jantar ", Laços de família (1960). Une lecture de la nouvelle de Clarice

Lispector

"O jantar", Laços de família (1960). Una lectura de la novela corta de Clarice Lispector

“O jantar”, Laços de família (1960). A Reading of Clarice Lispector's Short Story

\section{Claire Williams}

\section{(2) OpenEdition}

\section{Journals}

\section{Edição electrónica}

URL: https://journals.openedition.org/hispanismes/597

DOI: 10.4000/hispanismes.597

ISSN: 2270-0765

\section{Editora}

Société des Hispanistes Français

\section{Refêrencia eletrónica}

Claire Williams, " "O jantar", Laços de família (1960)», HispanismeS [En ligne], 15 | 2020, mis en ligne le 01 juin 2020, consulté le 31 juillet 2021. URL : http://journals.openedition.org/hispanismes/597 ; DOI : https://doi.org/10.4000/hispanismes.597

Este documento foi criado de forma automática no dia 31 julho 2021.

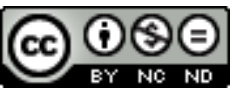

Les contenus de cette revue sont mis à disposition selon les termes de la Licence Creative Commons Attribution - Pas d'Utilisation Commerciale - Pas de Modification 4.0 International. 


\title{
“O jantar”, Laços de família (1960)
}

\author{
Uma leitura do conto de Clarice Lispector ${ }^{1}$ \\ "O jantar », Laços de família (1960). Une lecture de la nouvelle de Clarice \\ Lispector \\ "O jantar", Laços de família (1960). Una lectura de la novela corta de Clarice \\ Lispector \\ “O jantar”, Laços de família (1960). A Reading of Clarice Lispector's Short Story
}

\section{Claire Williams}

\section{Ingredientes: 0 enredo e as personagens}

1 No conto "O Jantar", como na maioria dos contos de Laços de familia, tanto o enredo como o elenco parecem simples: num restaurante, um homem (o narrador) janta sozinho ${ }^{2}$. Um homem mais velho chega fora do horário normal, chamando a atenção do outro, janta também sozinho, e vai embora ${ }^{3}$. 0 narrador fica fascinado e observa cada movimento do outro. Os garçons rendem seus serviços, obedecendo os pedidos e as necessidades do cliente. Uma mulher magra de chapéu, sentada numa mesa entre os dois homens, ri várias vezes.

2 Estamos aparentemente diante de uma cena de vida normal, banal, quotidiana. Todos estão jantando. Mas nas mãos de Clarice Lispector um jantar se transforma numa experiência angustiante, traumatizante. Os personagens estão num lugar público, e seu comportamento é visível e sujeito ao julgamento de outros. Têm a obrigação social de seguir as regras de comportamento desta sociedade ${ }^{4}$. Durante a refeição, devorada vorazmente, o homem observado (que, como o narrador, chamarei "o velho"), passa por pensamentos e emoções fortes que eventualmente lhe provocam uma lágrima, porém rapidamente se recompõe. Mais significante do que a narração detalhada do ritual da ingestão são as várias reações do narrador às ações do velho. De vez em quando, dirige-lhe uma frase agressiva imaginária em que o ameaça, despreza, menospreza. Mas só imaginárias: nunca teria a coragem de atacar, nem menos de falar a um monstro tão forte e sólido. 0 narrador considera o velho uma espécie de emblema 
ou cume de masculinidade hegemônica e poder físico e econômico, que, sendo tão diferente dele próprio (silencioso, sensível e bem-comportado, "pálido" e "perdido" [p. 70]), parece desafiá-lo na sua masculinidade e até na identidade: "Eu não podia mais, a carne no meu prato era crua, eu é que não podia mais. Porém ele - ele comia" (p. 71)5.

\section{Entrada: Biografia do conto}

3 "O jantar" foi um dos primeiros contos publicados na imprensa brasileira por Clarice, durante o período em que residia em Berna, capital da Suíça, onde seu marido diplomata foi enviado. O seu primeiro romance, Perto do Coração Selvagem (1943), fora recebido com aplausos impressionados e alguma perplexidade: ninguém tinha lido uma escrita parecida. O texto descreve a evolução social, amorosa e linguística de Joana, que questiona tudo à sua volta e não se encaixa na sociedade em que vive, e a narrativa entra e sai da consciência da protagonista, ora na terceira pessoa, ora na primeira.

Europa ao lado do marido, Clarice continuou a escrever, sobretudo em Berna, onde vivia uma vida solitária e tediosa, como confiava nas cartas que escrevia às irmãs e aos amigos ${ }^{6}$. Em 1946, publicou $O$ Lustre: outro romance estranho e psicológico, que trata dos sentimentos e das sensações da protagonista, Virgínia. Não sabemos se Clarice escrevia contos ao mesmo tempo em que escreveu esse romance e o próximo, A Cidade Sitiada (1949). Neste último, a protagonista Lucrécia é uma mulher fútil e sem inteligência, que sente mais afinidade com objetos inúteis e decorativos do que com outras pessoas. $O$ conto bem podia ser uma cena extraída de um dos textos mais longos.

"O jantar" saiu pela primeira vez no suplemento "Letras e Artes" do jornal carioca A Manhã, em 13 de outubro de 1946; depois foi recolhido na pequena coletânea Alguns Contos (1952), encomendada pelo Ministério da Educação; e foi inserido definitivamente em Laços de família em 1960. Ocupa um lugar privilegiado no centro do livro: é o sétimo conto de treze - o fulcro, ou a dobradiça da coletânea. Terá esta colocação algum sentido especial? o conto se destaca dos outros treze por várias razões: é o único com narração em primeira pessoa, trata principalmente de personagens masculinos e parece não ter nenhum "laço" com tema da coletânea: a família ${ }^{7}$. Aliás, em relação aos outros contos, recebeu pouca atenção crítica.

\section{Prato principal: leitura de "O jantar"}

6 Praticamente não há neste conto um enredo tradicional, com começo, meio e fim: tudo acontece em relação e em reação ao velho e às suas ações. Talvez possamos considerar que a lágrima e o "gesto de pensamento" (p. 71) do velho indiquem dois momentos, transitórios, de outra realidade possível, de conexão e comunicação entre seres humanos, se o velho ceder às emoções. Reviravolta? Epifania? Confissão que a vida é insuportável? Não; o velho se recompõe. O narrador está fisicamente afetado pelo que viu: nauseado, empalidecido.

7 Também em termos de cenário não é um conto convencional: estamos num restaurante bastante anônimo (embora a possibilidade de jantar fora já indique algum poder econômico), e os marcadores deícticos nos colocam "aqui" e "agora", com um "eu", um "ele" e "nós". A repetição de "ainda" nos últimos parágrafos sugere que algo vai ou 
poderia acontecer. $\mathrm{O}$ uso do imperfeito do conjuntivo (“como se...") significa hipóteses, desejos, mas não a realidade: parece, mas não é.

$\mathrm{O}$ ambiente é tenso. Está-se a ponto de uma crise. Uma série de movimentos bruscos (narrados no pretérito) interrompem outros mais prolongados (expressos no imperfeito): o velho entra em cena subitamente, abre os olhos com "brusquidão" e um garfo cai, ou pega rápido no guardanapo, come vigorosamente e de repente se imobiliza. O garçom de casaca passa entre os dois homens, bloqueando a visão. 0 narrador observa com o garfo suspenso no ar, esperando atento: "Parei em guarda". Fica agora tenso, agora aliviado.

9 É um conto que chama especial atenção aos movimentos do corpo: principalmente olhos e mãos, mas também a boca, as sobrancelhas, o peito, a garganta... o comer, e o respirar. Numa sala cheia de pessoas sentadas, servidas por garçons silenciosos e subservientes, só o velho tem a liberdade de andar onde e quando quiser. Mesmo assim, ele tem dificuldade em controlar o corpo e a cara agitados. Mexe e imobiliza-se. Come agressivamente, e para: "Sua violenta potência sacode-se presa" (p. 70) ${ }^{8}$. Ele fecha longamente os olhos, (para evitar distrações?), olha "fixo na luz do teto" (p.70), "comprime as órbitas dos olhos" (p. 70), franze as sobrancelhas e limpa os olhos com o guardanapo. Os dois homens parecem refletir-se num espelho. Às vezes o narrador sente no seu próprio corpo as mesmas sensações que o velho: "[ele] se imobiliza de novo como se tivesse o peito contraído e barrado. [...] Abandono com certa decisão o garfo no prato, eu próprio com um aperto insuportável na garganta" (p. 70). Mais frequentemente, as ações extravagantes do velho chocam o narrador, que faz exatamente o contrário: o velho parece não querer ver, enquanto o narrador vê tudo; $\mathrm{e}$ quer comer tudo, enquanto o narrador fica enjoado e para de comer.

O jantar do velho é um espetáculo que o narrador apresenta ao leitor como se estivesse ao nosso lado, apontando com os advérbios "Ei-lo" e "Eis", e utilizando efeitos de pontuação (por exemplo, as reticências), assim dando uma sensação de espontaneidade e suspense à narração. Há dois momentos climáticos na performance (que o velho nem sabe que está dando, e, se soubesse, não se importaria) que são expressões corporais espontâneas e somáticas: primeiro a lágrima espremida, quase invisível, mas testemunhada pelo narrador com triunfo, "eu vi. Vi a lágrima" (p. 70). Segundo, o gesto: "Com a mão pesada e cabeluda, onde na palma as linhas eram cravadas com tal fatalidade, faz um gesto de pensamento. Diz com a mímica o mais que pode, e eu, eu não compreendo" (p. 71). o velho "amplo e sólido" tem um ponto fraco: experimenta sensações e emoções, pensa e tenta comunicar. Tem "suas profundezas" (p. 70). Tenta escondê-lo, mas vimos provas de que é humano. Os seus esforços hercúleos para retomar o controle do corpo e voltar ao normal fascinam o narrador, cujas emoções oscilam entre abatimento, alívio e fúria. O velho quase engasga, "faz um gesto de esforço terrível para engolir" (p. 71) a comida, e isto parece ser uma metáfora para a dificuldade de "engolir" o insuportável sistema que impõe regras de comportamento que oprimem o individual, e para os esforços que fazemos todos os dias para superar dificuldades. Ele quer ver a cara verdadeira, atrás da máscara (que caiu brevemente duas vezes) mas o velho não permite:

Procuro aproveitar este momento, em que ele não possui mais o próprio rosto, para ver afinal. Mas é inútil. A grande aparência que vejo é desconhecida, majestosa, cruel e cega. O que eu quero olhar, diretamente, pela força extraordinária do ancião, não existe neste instante. Ele não quer (p. 72). 
11 Mesmo que o velho não esteja consciente da presença do narrador, nos olhos deste estabeleceu-se uma relação e são unidos pela solidão: “Ambos permanecemos em silêncio no centro do salão" (p. 72). Mas isto não é um caso de amor à primeira vista, nem um duelo entre inimigos. Os garçons e a mulher magra de chapéu funcionam como obstáculos interrompendo à visão contínua do velho; aliás, este é o papel de esta personagem feminina:

O papel dessa mulher, personagem secundário a quem só com muito esforço damos alguma atenção, é, no entanto, decisivo. Ali postada como um lenço, ou um véu, ela é o anteparo que impede a explosão da cena. o eixo, em torno do qual os dois se movimentam e sem o qual talvez se chocassem ${ }^{9}$.

12 Não sabemos nada sobre a vida nem a aparência do narrador, mas dependemos dele para ver e entender o mundo do conto. Concluímos que ele deve ser uma figura completamente diferente ao velho, a polaridade oposta, que lhe atrai e repele ao mesmo tempo. Esta oposição entre os protagonistas vê-se replicada nas muitas oposições binárias no texto: visível/invisível, sólido/líquido, movimento/paralisia, força/fraqueza, dentro/fora ${ }^{10}$.

Desde o princípio, o velho caracteriza-se pelas referências à idade, ao porte físico, e à riqueza.

Ele entrou tarde no restaurante. Certamente ocupara-se até agora em grandes negócios. Poderia ter uns sessenta anos, era alto, corpulento, de cabelos brancos, sobrancelhas espessas e mãos potentes. Num dedo o anel de sua força. Sentou-se amplo e sólido (p. 69).

O narrador deduz que "certamente" foram os "grandes" negócios que causaram o atraso e obrigam o velho a escolher e comer mais rápido do que devia. Os cabelos brancos, solidez e força são atributos de um rei, ou até de um deus. Impressionado pela aparição de um homem tão conspícuo, o narrador para de comer, o garfo no ar, e observa-o obsessivamente. Causa-lhe alguma angústia a maneira desdenhosa com que o velho trata os garçons “cortês". Estes reconhecem o seu poder e servem-lhe assíduos, conciliadores quando algo corre mal. Vemos aqui um servilismo interesseiro, porque calculam que "lá estava seguramente um senhor de boas gorjetas, um desses velhos que ainda estão no centro do mundo e da força” (p. 71).

No começo, emanam do velho autoridade e força, mas isso se perde momentaneamente no curso do conto: "ele se desmoronava a olhos vistos" (p.72) ("os traços caídos" [p. 72], como se se derretesse); “parece mais fraco" (p. 72); acaba uma "ruína” (p. 73); contrai-se todo; fica "mais velho muitos anos" (p. 72) ao botar os óculos. Passa por momentos de dor e angústia, e é tão poderoso e adepto a esta situação que consegue ultrapassar tudo, mesmo o "insuportável". O narrador o chama mais frequentemente de "ele", ou "o velho", mas também por epítetos alegóricos de poder (físico e econômico), violência, sabedoria, e até terror e perigo: "Plutão" (p. 71), ${ }^{11}$ "o ancião" (p. 72), “o patriarca" (p. 72), “o grande cavalo" (p.72), ${ }^{12}$ e "o velho comedor de crianças"13 (p. 72), “capaz de apunhalar qualquer um de nós” (p. 73).

Roberto Corrêa dos Santos comenta que a narrativa se desenvolve como um processo cinematográfico:

O olho do narrador seria a câmera, movendo-se ora mais lenta, ora mais rápida, desviando-se por vezes de seu centro de interesse para repousar de relance sobre alguns poucos componentes visuais do ambiente. [...] Aumento ou diminuição de sons estreitam-se aos sentimentos daquele que observa. No mais, é pelo silêncio que se cria a atmosfera da narrativa ${ }^{14}$. 
17 Tanto a comida e o vinho que selecionou do cardápio, como a maneira em que ele os devora são fascinantes para o narrador, que relata o ato de ingestão como se fosse um etnógrafo estudando um ritual:

Ei-lo de olhos fechados mastigando pão com vigor e mecanismo, os dois punhos cerrados sobre a mesa. [Ele] virava subitamente a carne de um lado e de outro, examinava-a com veemência [...], levava um pedaço a certa altura do rosto e, como se tivesse que apanhá-lo em voo, abocanhou-o num arrebatamento de cabeça. [Ele] apanha uma garfada de salada com o corpo todo e come inclinado, o queixo ativo, o azeite humedecendo os lábios. [Ele] misturava à carne os goles de vinho na grande boca e os dentes postiços mastigavam pesados [...], bebe de olhos fechados, em rumorosa ressurreição [...]. Vem a sobremesa, um creme derretido, e eu me surpreendo pela decadência da escolha. Ele come devagar, tira uma colherada e espia o líquido pastoso escorrer. Ingere tudo, porém faz uma careta e, crescido, alimentado, afasta o prato (p. 69-72).

$18 \mathrm{O}$ ato de comer representa a ingestão de objetos pelo corpo; é um ato fundamental para a maneira em que o "eu" se relaciona com o mundo. O corpo do velho lembra os corpos grotescos criados por Rabelais, na interpretação de Mikhail Bakhtin:

The distinctive character of this body is its open unfinished nature, its interaction with the world. These traits are most fully and concretely revealed in the act of eating; the body transgresses here its own limits: it swallows, devours, rends the world apart, is enriched and grows at the world's expense. The encounter of man with the world, which take place inside the open, biting, rending, chewing mouth, is one of the most ancient, and most important, objects of human thought and imagery. Here man tastes the world, introduces it into his body, makes it part of himself. [...] Man's encounter with the world in the act of eating is joyful, triumphant; he triumphs over the world, devours it without being devoured himself ${ }^{15}$.

19 O conto representa duas maneiras de estar no mundo: o velho come com entusiasmo e apetite, sente a "plena glória do jantar" (p.69); o narrador fecha o corpo, rejeita "a carne e seu sangue" (p. 73), ingere o mundo pelo olhar e a mente.

Nota-se na citação acima, tirada do conto, a frequência de verbos no imperfeito e gerúndios, que tornam a cena mais viva e dão extensão aos movimentos. Clarice mistura os tempos verbais para amplificar o ambiente de confusão e angústia. Nas palavras de Roberto Corrêa dos Santos:

Alternando-se, permanentemente, por todo texto, tanto os sujeitos dos enunciados, quanto a forma verbal que se lhes refere, cria-se o próprio clima de conflito. E de tal forma este se intensifica que, no encerramento do conto (último parágrafo), verifica-se a junção desviada de tempos verbais aparentemente incompatíveis, construindo-se, pela dissonância, o estado do narrador [...] $]^{16}$.

21 O jantar em si é uma combinação de elementos simples (pão, carne, salada, sobremesa cremosa, vinho tinto): animal e vegetal, doce e salgado, saudável e luxurioso, e o pão e vinho da Eucaristia que lhe trazem "rumorosa ressurreição" (p. 72). Porém, isto não é um ritual de adoração de um deus. É um ato violento de sobrevivência (o esforço de sustentar o corpo e manter o poder), e de prazer na experiência gustativa. E talvez, simbolicamente, uma alusão à "Última Ceia" que precedeu eventos monumentais.

O velho come primeiro de maneira automática, depois brutalmente, como um animal apanhando a presa: o corpo todo se entrega ao processo, excessivo. Ele demostra maneiras à mesa nada menos que rabelaisianas, de tão grotescas (lábios oleosos, a boca aberta, a língua de fora, a estalar, dentes postiços), mas por ser um importante e rico homem de negócios ninguém lhe censura, nem ele se importa. A cara se contorciona, 
como a do cego mascando chicletes no conto "Amor"; são caretas grotescas que desmentem a dor que o narrador acredita que tenha por dentro, os soluços que imagina ouvir (p. 72), que está tentando conter. As mãos também são o foco do narrador, mãos “potentes" (p. 69), "grandes" (p. 69), "cabeludas" (p. 70), "vigorosas" (p. 73), “a mão quadrada" (p. 73), "os dois punhos cerrados" (p.69). As mãos lhe servem para manipular os talheres e o copo, para limpar os olhos, para segurar a cabeça em momentos de desespero, e não duvidemos que tenham o poder de destruir, apunhalar ou assassinar.

o corpo cresce, enche, treme, mexe e para, desinflando quando as emoções são demasiado fortes. Entretanto, o narrador perde o apetite e sente a percepção alterada: "Eu não podia mais, a carne no meu prato era crua, eu é que não podia mais. Porém ele - ele comia. [...] Estou tomado pelo êxtase arfante da náusea. Tudo me parece grande e perigoso" (p. 71).

No final do conto o narrador rejeita a comida completamente porque não quer ser como o velho: "Quando me traíram ou assassinaram, quando alguém foi embora para sempre, ou perdi o que de melhor me restava, ou quando soube que vou morrer - eu não como. Não sou ainda esta potência, esta construção, esta ruína. Empurro o prato, rejeito a carne e seu sangue" (p. 73).

Rejeita o poder que ele ainda não atingiu, e depois de observar a violência que isto implica, ele pode não querer assumir ${ }^{17}$.

É também uma rejeição do que o ritual de ingestão de comida representa: uma reconstrução da identidade através da incorporação de carne e sangue, construindo-se através da carne e do sangue dos outros, ou seja, canibalismo. O ritual em "O jantar" é uma aniquilação da comida para refortalecer o "eu", algo que o narrador não consegue fazer.

\section{Sobremesa: ecos ou déjà-vus}

Lembremos outros contos de Laços de família em que o ritual de comensurabilidade se observa. Em "Devaneio e embriaguez de uma rapariga", a protagonista e o marido jantam num restaurante, e ela olha com desprezo "pelas pessoas secas [...], nenhum homem que fosse homem a valer, que fosse triste mesmo" (p. 13). O velho mastigando a comida de olhos fechados e as mudanças bruscas de tom de "O jantar" lembram a figura do cego mascando chicletes em "Amor" (p. 19) que tanto surpreende Ana ("como se ele a tivesse insultado" [p.19]). Em "Feliz Aniversário", a festa que simboliza a união da família resulta em desastre. A mera expectativa de sair para jantar com amigos, e a associada pressão de se comportar de acordo com as regras de uma situação social contribuem à recaída de Laura em "A imitação da rosa". Em Perto do coração selvagem, Joana observa uma cena quase igual:

Um dia [...] via um homem guloso comendo. Espiara seus olhos arregalados, brilhantes e estúpidos, tentando não perder o menor gosto do alimento. $E$ as mãos, as mãos. Uma delas segurando o garfo espetado num pedaço de carne sangrenta [...] e a outra crispando-se na toalha [...]. Joana estremecera arrepiada diante do seu pobre café. Mas não saberia se fora por repugnância ou por fascínio e voluptuosidade. Por ambos certamente. Sabia que o homem era uma força. Não se sentia capaz de comer como ele, era naturalmente sóbria, mas a demonstração a perturbava ${ }^{18}$. 
Como o narrador de "O jantar", a moça se sente tanto atraída como repugnada pelo espetáculo do homem a comer, rejeita esse tipo de comportamento, mas retém uma sensação de perturbação; aliás, os leitores também retêm.

\section{Café: tentativas de conclusões}

Como tirar conclusões sobre um conto que deixa o narrador e o leitor sozinhos no restaurante após a saída do velho, com o prato a sua frente, a comida rejeitada. Talvez o conto em si represente o processo de leitura como se fosse um jantar: observamos os personagens, que ignoram a nossa existência, tentamos compreendê-los e simpatizar com eles. Gritamos, fazemos perguntas retóricas, mas eles não respondem. Saboreamos as palavras e digerimos as possíveis interpretações.

Poderia igualmente ser uma crítica das pressões do sistema social patriarcal, os papéis sexuais impostos para quem quer participar plenamente. "O jantar" mostra que não são somente as mulheres que sofrem com as expectativas da sociedade. Os homens também experimentam pressões insuportáveis - mesmo estando numa posição de mais poder só por serem homens. A frase do narrador, "Mas eu sou um homem ainda" (p. 73), é ambígua. $O$ velho desaparece.... O "Mas" significa uma surpresa: mesmo sem a presença hipermasculina do outro, o narrador mantém o seu estado biológico de macho. Ou talvez signifique o contrário, um lamento por ser "ainda" homem? Mesmo depois da experiência estranha de observar o jantar, que o fez passar por tantas emoções fortes, o narrador é um homem ainda. Sofreu por dentro, mas nada mudou por fora.

31 As últimas frases são difíceis de interpretar: "Quando me traíram ou assassinaram, quando alguém foi embora para sempre, ou perdi o que de melhor me restava, ou quando soube que vou morrer - eu não como" (p. 73). o narrador está morto? Estamos no inferno, o reino de Plutão? O narrador se está identificando com Jesus Cristo, que jejuou no deserto, e que foi traído e assassinado, antes da ressurreição? Este narrador pelo menos tem o luxo de poder escolher se vai comer ou não e, de qualquer maneira, não é obrigado a comer com a agressividade do velho, que talvez tenha comido "depressa demais" porque tem de voltar aos "grandes negócios".

O que quer comunicar Clarice neste conto singular? Que não só as mulheres, mas os homens também sofrem por viver presos num sistema patriarcal que impõe certos comportamentos e proíbe outros. Os homens, certamente nos anos 1940 e 1950 e também meio século depois, vivem uma vida social e pública em que não podem transparecer emoções fortes, nem sinais de fraqueza. $O$ velho interpreta um papel e o conto mostra os pequeníssimos momentos em que ele quase se dá conta de que está interpretando esse papel, e que há outros papéis possíveis. 0 narrador reconhece o estereótipo, e sabe que para chegar ao mesmo ponto terá que reprimir os próprios desejos e a identidade.

E nós, leitores? Quando acabamos o conto estamos abertos ao mundo, prontos para devorá-lo, ou perdemos o apetite? 


\section{BIBLIOGRAFIA}

Mikhail BAKHTIN, Rabelais and His World, trad. Helen Iswolsky (Bloomington: Indiana University Press, 1984)

José CASTELLo, “Observação do insuportável”, Suplemento Pernambuco [on-line], Brasil, Recife (s/d), [disponível 20/09/2020], <URL: https://www.suplementopernambuco.com.br/ediçõesanteriores/120-colunas/jose-castello/1901-observação-do-insuportável.html>

Roberto CORRÊA DOS SANTOS, “Leitura do conto 'O jantar”, in Clarice, ela, Rio de Janeiro: Instituto Moreira Salles, 2012, p. 92-115 [disponível 20/092020], <URL : https://claricelispectorims.com.br/ wp-content/uploads/2016/11/book_34.pdf >

Arnaldo FRANCO JÚNIOR, “Da crítica ao mau gosto: 'O jantar', de Clarice Lispector”, Revista de Letras, vol. 41/42, (2001/2002), p. 139-150.

Clarice LISPECTOR, Laços de família, Lisboa, Cotovia, 2006.

Clarice LISPECTOR, Minhas queridas, org. Teresa Montero, Rio de Janeiro, Rocco, 2007.

Clarice LISPECTOR, Correspondências, org. Teresa Montero, Rio de Janeiro, Rocco, 2002.

Cláudia Pazos Alonso, "Defamiliarization and Déjà Vu in Laços de família", Cláudia Pazos Alonso e Claire Williams (ed), Closer to the Wild Heart: Essays on Clarice Lispector, Oxford, MHRA/Legenda, 2002, p. 73-89.

Marta PЕІХОТО, Ficções apaixonadas: gênero, narrativa, e violência em Clarice Lispector, trad. Maria Luiza X. de A. Borges, Rio de Janeiro, Vieira \& Lent, 2004.

Carlos MENDES DE SOUSA, “Posfácio: A íntima desordem dos dias”, Clarice Lispector, Laços de família, Lisboa, Cotovia, 2006, p. 127-48.

Claire WILLIAMS, The Encounter Between Opposites in the Works of Clarice Lispector, Bristol, HiPLAM, 2006.

\section{NOTAS}

1. Este ensaio se baseia em parte numa seção do meu livro The Encounter Between Opposites in the Works of Clarice Lispector, Bristol, HiPLAM, 2006. Agradeço à valiosa ajuda de Joana Perrone na revisão deste artigo.

2. Clarice LISPECTOR, "O jantar", Laços de família, Lisboa, Cotovia, 2006, p. 69-73. Os números de página que cito entre parênteses neste ensaio se referem a esta edição.

3. Em vez de sentar-se a volta da mesa, como fazem as famílias, estes senhores estão definitivamente sós. Comenta Carlos MENDES DE SOUSA que "mais do que o convívio, a refeição sublinha antes o vazio e a ausência", "Posfácio: A íntima desordem dos dias", Clarice Lispector, Laços de família, p. 144-145.

4. Lembro-me de uma cena chocante no filme dinamarquês The Square (2017), de Ruben ösTLUND, em que um jantar formal numa galeria de arte é interrompido por uma performance (um homem-chimpanzé), que agride os convidados, transgredindo as fronteiras das boas maneiras até o ponto de ninguém saber se a performance tenha acabado ou não.

5. Várias vezes o narrador repete o pronome pessoal "eu" na mesma frase, para chamar atenção sobre as façanhas realizadas e a individualidade: foi ele quem fez, só ele. 
6. Cf. Clarice LISPECTOR, Correspondências, Teresa Montero (org.), Rio de Janeiro, Rocco, 2002; Clarice LISPECTOR, Minhas queridas (org.), Teresa Montero, Rio de Janeiro, Rocco, 2007.

7. Cláudia Pazos Alonso sugere que "O jantar" marca uma mudança de foco na coletânea: depois de mostrar os efeitos nocivos das convenções sociais nas mulheres casadas contemporâneas na primeira metade, ela analisa a maneira pela qual os papéis sociais são internalizados por todos não só as mulheres. Cláudia PAZOS ALONSO "Defamiliarization and Déjà Vu in Laços de família", Cláudia Pazos Alonso e Claire Williams (eds.), Closer to the Wild Heart: Essays on Clarice Lispector, Oxford, Legenda, 2002, p. 77.

8. Lispector utiliza um vocabulário que acentua a violência de atos que normalmente são automáticos e calmos: por exemplo "brusquidão" (p. 69), "veemência" (p. 69), "brutalidade" (p. 70), "assaltar" (p. 70), "bater" (p. 71).

9. José CAStello, “Observação do insuportável”, Suplemento Pernambuco [on-line], Brasil, Recife (s/ d), [disponível 20/09/2020], <URL: https://www.suplementopernambuco.com.br/ediçõesanteriores/120-colunas/jose-castello/1901-observação-do-insuportável.html>

10. Sobre as oposições binárias no conto, leia-se o artigo de Arnaldo FRANCO JÚNIOR, "Da crítica ao mau gosto: 'O jantar', de Clarice Lispector”, Revista de Letras, nº 41/42 (2001/2002), p. 139-150.

11. Na mitologia grega, Plutão foi o deus dos mortos e da riqueza. Será que este restaurante é uma recriação do inferno ou do purgatório?

12. O cavalo é um símbolo de liberdade nos romances Perto do coração selvagem e A cidade sitiada.

13. Este epíteto lembra a antropofagia que é tão emblemática na cultura brasileira.

14. Roberto CORRÊA DOS SANTOS, "Leitura do conto 'O jantar"', Clarice, ela, Rio de Janeiro, Instituto Moreira Salles, 2012, p. 92-115. [disponível 20/09/2020], <URL: https:// claricelispectorims.com.br/wp-content/uploads/2016/11/book_34.pdf $>$.

15. Mikhail BAKHTIN, Rabelais and His World, trad. Helen Iswolsky, Bloomington, Indiana University Press, 1984, p. 281.

16. Ibid., p. 99-100.

17. Marta PЕIXОТо, Ficções apaixonadas: gênero, narrativa, e violência em Clarice Lispector, Maria Luiza X. de A. Borges (trad.), Rio de Janeiro, Vieira \& Lent, 2004, p. 93-94.

18. Clarice LISPECTOR, Perto do coração selvagem, Rio de Janeiro, Francisco Alves, 1994 [1943], p. 26.

\section{RESUMOS}

Dans cet article je propose une lecture de la nouvelle de Clarice Lispector « O jantar », qui intègre le recueil Laços de família (1960). Je prête une attention particulière à l'usage de la langue, à la structure, aux thèmes et aux images, pour explorer les allusions et suggérer des significations possibles.

This article provides a close reading of Clarice Lispector's short story "O jantar" from the 1960 collection Laços de familia, with attention to language, structure, themes and images, in order to explore its allusions and suggest potential meanings. 
ÍNDICE

Mots-clés: Laços de família, O jantar, identité, masculinité, le regard, grotesque

Keywords: Laços de família, o jantar, identity, masculinity, the gaze, the grotesque

\section{AUTOR}

CLAIRE WILLIAMS

University of Oxford 